\title{
Genetic parameters and trends for lactation length in the first three lactations of Holstein cows
}

\author{
Navid Ghavi Hossein-Zadeh \\ Department of Animal Science, Faculty of Agricultural Sciences, University of Guilan, Rasht, Iran
}

\begin{abstract}
Calving records from the Animal Breeding Center of Iran collected from January 1986 to December 2007 and comprising 492424 calving events of Holsteins from 1413 dairy herds were analysed using linear animal models to estimate genetic parameters for lactation lengths in the first three lactations of Holstein cows. Genetic trends were obtained by regressing yearly mean estimates of breeding values on calving year. Heritability estimates for lactation lengths varied from 0.03 to 0.04 across the parities. Estimates of genetic correlations between lactation lengths in different parities ranged from 0.35 to 0.53 . There was decreasing genetic trend for lactation length at parity 3 and there were increasing genetic trends for lactation lengths at parities 1 and 2 over the years $(P<0.05)$. The low estimates of heritabilities obtained in this study imply that much of the improvement in lactation lengths could be attained by improvement of production environment rather than genetic selection.
\end{abstract}

Keywords: lactation length, genetic parameter, genetic trend, phenotypic trend, dairy cow

\section{Introduction}

Precise and accurate knowledge of genetic parameters are of paramount importance for planning appropriate selection and breeding strategies for the genetic improvement of dairy animals (Choudhary et al. 2003). An important aspect of formulation of breeding plan for animal or plant improvement is selection which amounts to choice of parents to produce the next generation. A basic prerequisite to the planning of breeding program is that of the total variability existing in the population and how much of this is caused by differences in the genetic make-up of the individuals. A quantitative measure of this is provided by heritability. With the help of heritability one can predict the breeding value of the individual. The magnitude of heritability dictates the choice of the selection method and breeding system (Paul et al. 2003).

An interesting aspect of milk production in tropical dairy cattle is length of lactation. Variability appears much greater in tropical than in temperate dairy cattle with the former having relatively high proportions of short lactations. The difference is caused by both genetic and non-genetic factors (Syrstad 1993). Most European dairy cattle in temperate zones produce milk at profitable levels for 305 days. This length is the most common for evaluating performance of dairy cows and it corresponds to a 12 month calving interval. Cows of temperate dairy breeds under intensive management usually continue to lactate until milk secretion is suppressed by the advanced stage of gestation. If a cow does not dry off naturally, it is usually forced dry five to six weeks before the expected calving date in 
order to provide a sufficient rest prior to the ensuing lactation. Length of lactation, therefore, is almost completely determined by length of calving interval. In tropical cattle, however, milk production often ceases several months before next calving and before the depressing effect of gestation on milk production is noticeable (Syrstad 1993). Length of lactation, therefore, is not so greatly influenced by calving interval. Lactation length in high-producing cows has increased over the last decade in some populations (Gonzalez-Recio et al. 2004, Steri et al. 2010), and presently in many countries cows have lactations extended beyond 305 days (Vargas et al. 2000). It results from extending days open, mainly because of reproductive difficulties. So, extending lactations becomes a part of contemporary management strategy (Tarazon-Herrera et al. 2000, Gonzalez-Recio et al. 2006, Dematawewa et al. 2007).

Lactation length in tropical cattle is a measure of persistency and it is a heritable trait. But, estimates of genetic parameters and genetic trends for lactation length are rare in the literature. Therefore, the objective of this study was to estimate genetic parameters and trends for lactation length in the first three lactations of Iranian Holsteins over a 22 year period from 1986 to 2007.

\section{Material and methods}

\section{Data set}

Calving records from the Animal Breeding Center of Iran, collected from January 1986 to December 2007 and comprising 492424 calving events of Holsteins from 1413 dairy herds were included in the data set. The herds used in this study are among the purebred Holsteins which are managed under conditions similar to most other developed countries and are under official performance and pedigree recording. The data included animal registration number, herd, calving date, parity, calving age and lactation length. The pedigree information used in this study was extracted from the database used for the national genetic evaluation of dairy traits in Iran, which had been provided by the Animal Breeding Center of Iran and reported by Ghavi Hossein-Zadeh et al. (2009) in previous study. Records were eliminated if no registration number or no lactation length record was present for a given cow. Ages at calving were required to be between 20 and 40, 28 and 49, and 40 and 68 months in lactations one, two, and three, respectively. Months of birth were grouped into four seasons: January through March (winter), April through June (spring), July through September (summer), and October through December (fall).

\section{Statistical models of analysis}

The following univariate animal model was fitted to estimate variance components and heritabilities separately for first parity lactation length (LL1), second parity lactation length (LL2) and third parity lactation length (LL3):

$$
y_{i j k l}=\mu+a_{i}+h y s_{j}+b_{1 k} A g e_{k}+b_{2 k}\left(\text { Age }_{k}\right)^{2}+e_{i j k l}
$$

where $y_{i j k l}$ was single observation of lactation length affected by random additive genetic effect of animal $i\left(\mathrm{a}_{\mathrm{i}}\right)$ in fixed effects of herd-year-season of calving $j$ (hys), and the random effect of residual error $\left(e_{i j k l}\right)$. Also, $b_{\imath k}$ and $b_{\imath k}$ were regression coefficients on the two orders for age at calving $\left(\right.$ Age $\left._{k}\right)$. 
Bivariate or pairwise animal models were used to estimate genetic and phenotypic correlations between first-, second-, and third-parity lactation lengths. The models applied in pair-wise analyses were the same as those fitted for the genetic analysis of each trait in the univariate analyses and were, in matrix notation, as follows:

$$
\left[\begin{array}{l}
y_{1} \\
y_{2}
\end{array}\right]=\left[\begin{array}{ll}
X_{1} & 0 \\
0 & X_{2}
\end{array}\right]\left[\begin{array}{l}
b_{1} \\
b_{2}
\end{array}\right]+\left[\begin{array}{ll}
z_{1} & 0 \\
0 & Z_{2}
\end{array}\right]\left[\begin{array}{l}
u_{1} \\
u_{2}
\end{array}\right]+\left[\begin{array}{l}
e_{1} \\
e_{2}
\end{array}\right]
$$

where $y_{1}$ and $y_{2}$ were the vectors of observations for lactation lengths in different lactations; $b_{1}$ and $b_{2}$ denoted the fixed effects in the models with association matrices $X_{1}$ and $X_{2} ; u_{1}$ and $u_{2}$ were the vectors of direct genetic effects with the incidence matrices $Z_{1}$ and $Z_{2}$; and $\boldsymbol{e}_{1}$ and $e_{2}$ denoted the vectors of residual effects.

\section{Genetic analyses}

The linear univariate and bivariate animal model analyses were run using a restricted maximum likelihood method and average information algorithm (AIREML) of the MATVEC program (Wang et al. 2001) to obtain heritabilities and genetic correlations of lactation length in first, second, and third lactations. Genetic trends were obtained by regressing yearly mean estimates of breeding values on year of calving. Also, phenotypic trends were estimated using the linear regression of average phenotypic values on calving year.

\section{Results and discussion}

Summary statistics for LL1, LL2 and LL3 are shown in Table 1. Average lactation lengths were from 292.36 to 314.97 days and decreased from LL1 through LL3. The reported averages of lactation lengths in the current study (292.36 to 314.97 days) were generally consistent with the results of Ojango \& Pollott (2001) who reported the mean of lactation length was 300 days in Holstein-Friesian cows, but were lower than the report of Effa et al. (2011) and was greater than the results of Bajwa et al. (2004) who reported the means of lactation lengths as 346.4 and 248 days, respectively. There was more variation in LL1 than in LL2 and LL3 (Table 1) and this is expected because LL1 is represented by a more unselected part of the population compared to LL2 and LL3. Contrary to the current results, Effa et al. (2011) reported the means of lactation lengths increased from the first parity through to the fourth parity in Ethiopian dairy cows.

Table 1

Summary statistics for lactation length in the first three lactations of Iranian Holsteins from 1986 to 2007

\begin{tabular}{lcccc}
\hline Trait & $\mathrm{N}$ & Mean & SD & CV, \% \\
\hline LL1, days & 206582 & 314.97 & 107.96 & 34.28 \\
LL2, days & 167551 & 298.63 & 96.94 & 32.46 \\
LL3, days & 118291 & 292.36 & 93.90 & 32.12 \\
\hline
\end{tabular}

LL1: first parity lactation length, LL2: second parity lactation length, LL3: third parity lactation length

Estimates of heritabilities, genetic and phenotypic correlations for LL1, LL2 and LL3 in Holstein cows are presented in Table 2. Heritability estimate for LL1 and LL2 (0.04) was 
greater than the estimate for LL3 (0.03). The greatest phenotypic correlation was between LL2 and LL3 (0.15) and the greatest estimate of genetic correlation was between LL1 and LL2 (0.53). Effective breeding programs depend on the accuracy of genetic and phenotypic parameter estimates, which include heritability and correlation between traits (Ilatsia et al. 2007). Therefore, accurate estimation of these parameters will help to design an efficient breeding program for goal traits that are to be improved by selection. The low estimates of heritability obtained in this study could be attributable to the high phenotypic variance arising from large environmental variation. This, therefore, implies that much of the improvement in lactation length traits could be attained by improvement of production environment rather than selection, as suggested by other authors (van der Westhuizen et al. 2001). The heritability estimates for lactation length traits in the current study correspond with those reported by Ahmed et al. (2004) who reported the heritability estimate of 0.028 for lactation length in crossbred cattle of Bangladesh. Other authors reported higher estimates of heritabilities for lactation length than the estimates obtained in the current study. Ojango \& Pollott (2001) reported a low heritability estimate of 0.09 for lactation length in Holstein-Friesian cows. Rahman et al. (2007) reported the heritability estimate of 0.49 for first parity lactation length in dairy cattle of Bangladesh. Choudhary et al. (2003) estimated the heritability of first lactation length as 0.13 in Sahiwal cattle. In addition, Paul et al. (2003) reported the REML estimate of heritability for lactation length was 0.29 in the Kankrej breed of India. In general, several factors such as size of dataset, breed of the animal, genetic variation within population, management and environmental conditions, the method of estimating parameter, etc., would have affected the differences between estimations. The heritabilities of LL1 and LL2 were higher than that of LL3 in this study because the genetic variances for LL1 and LL2 were larger than that for LL3.

Table 2

Estimates of heritabilities (in bold on diagonal), genetic correlations (above the diagonal) and phenotypic correlations (below the diagonal) for lactation lengths in the first three lactations of Iranian Holsteins (standard error of heritability estimates are in brackets)

\begin{tabular}{|c|c|c|c|}
\hline \multirow[t]{2}{*}{ Trait } & \multicolumn{3}{|c|}{ Trait } \\
\hline & LL1 & LL2 & LL3 \\
\hline LL1 & $0.04(0.003)$ & 0.53 & 0.35 \\
\hline LL2 & 0.13 & $0.04(0.003)$ & 0.51 \\
\hline LL3 & 0.09 & 0.15 & $0.03(0.0002)$ \\
\hline
\end{tabular}

LL1: first parity lactation length, LL2: second parity lactation length, LL3: third parity lactation length

Inconsistent with the current study, other studies did not include more than one lactation length as different traits in a genetic evaluation; therefore, there were no estimates of correlations between lactation lengths at different parities in the literature. The medium to high genetic correlation between lactation length traits reported in this study implies that genes that positively influence lactation length in a parity would result in greater values of lactation length in other parities. The positive genetic correlations between lactation length traits are evidence for common genetic and physiological mechanism controlling these traits. Also, positive genetic correlation between the traits under study suggesting that selection of dairy cows in favour of or against LL1 (i.e., lengthening or shortening LL1, respectively) 
would also improve other lactation length traits. Also, estimates of phenotypic correlations between lactation length traits in this study were positive and low, indicating there was little association between phenotypic measurements of these traits.

Estimates of genetic and phenotypic trends for lactation length traits in Iranian Holsteins are shown in Table 3. The average annual phenotypic trends obtained from fitting linear regression of annual mean lactation lengths at parities 1 through 3 were significant $(P<0.05)$ and positive over the years (Table 3). On the other hand, there was decreasing genetic trend for lactation length at parity 3 and there were increasing genetic trends for lactation lengths at parities 1 and 2 over the years $(P<0.05)$. Phenotypic trends and mean estimated breeding values for lactation length traits by year of calving are shown in Figures 1 and 2, respectively. In general, there was a consistent phenotypic trend for LL1, LL2 and LL3 over the years from 1990 onwards (Figure 1). In general, there was a decreasing genetic trend for LL1 from 1991 to 1998, and then the genetic means of LL1 increased roughly from 1998 onwards. On the other hand, the genetic means of LL2 increased obviously from 1986 to 1994 and from 2000 to 2005, but decreased from 1995 to 2000 and from 2005 to 2007. Also, there was an increasing trend for the genetic means of LL3 from 1986 to 1997, and then a decrease occurred in from 1997 to 2001 (Figure 2). There were decreasing phenotypic trends for lactation length traits in this study and this would be contrary with the increase in the lactation length of cows with high production level in other countries at recent years (Steri et al. 2010). Therefore, decreasing phenotypic trends for lactation lengths over the years in under study population could result in lower milk yields compared to the populations with the positive phenotypic trends for lactation length (i.e., extended lactations). On the other hand, increasing genetic trends for LL1 and LL2 in this study could normally be concurrent with increasing genetic trend for milk yield in dairy cows. Consistent with the current result of decreasing genetic trend for LL3, Effa et al. (2011) showed negative annual genetic gains of about -3.348 days for lactation length in the Ethiopian dairy cows.

Table 3

Estimates of genetic and phenotypic trends $( \pm$ SE) for lactation lengths in the first three lactations of Iranian Holsteins*

\begin{tabular}{lccr}
\hline Trend & LL1 & Trait & \multicolumn{1}{c}{ LL3 } \\
\hline Genetic & $0.068 \pm 0.003$ & $0.038 \pm 0.004$ & $-0.007 \pm 0.003$ \\
Phenotypic & $1.185 \pm 0.373$ & $1.393 \pm 0.288$ & $0.831 \pm 0.390$ \\
\hline
\end{tabular}

LL1: first parity lactation length, LL2: second parity lactation length, LL3: third parity lactation length, *All coefficients were significant at $P<0.05$.

In conclusion, due to the low estimates of heritabilities for lactation length traits in this study, much of the improvement in lactation lengths could be attained by improvement of production environment rather than genetic selection. Therefore, direct genetic selection would have only limited effects on the lactation lengths in Iranian Holsteins. 


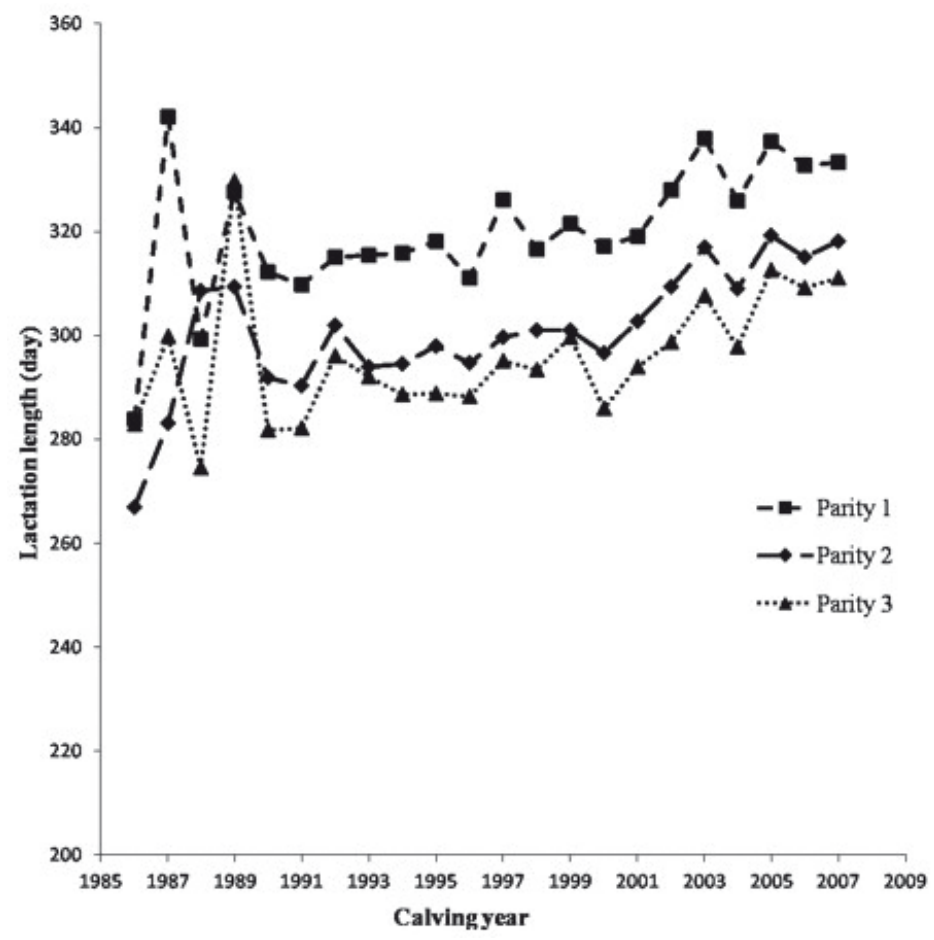

Figure 1

Phenotypic means of lactation lengths in the first three parities by year of calving.

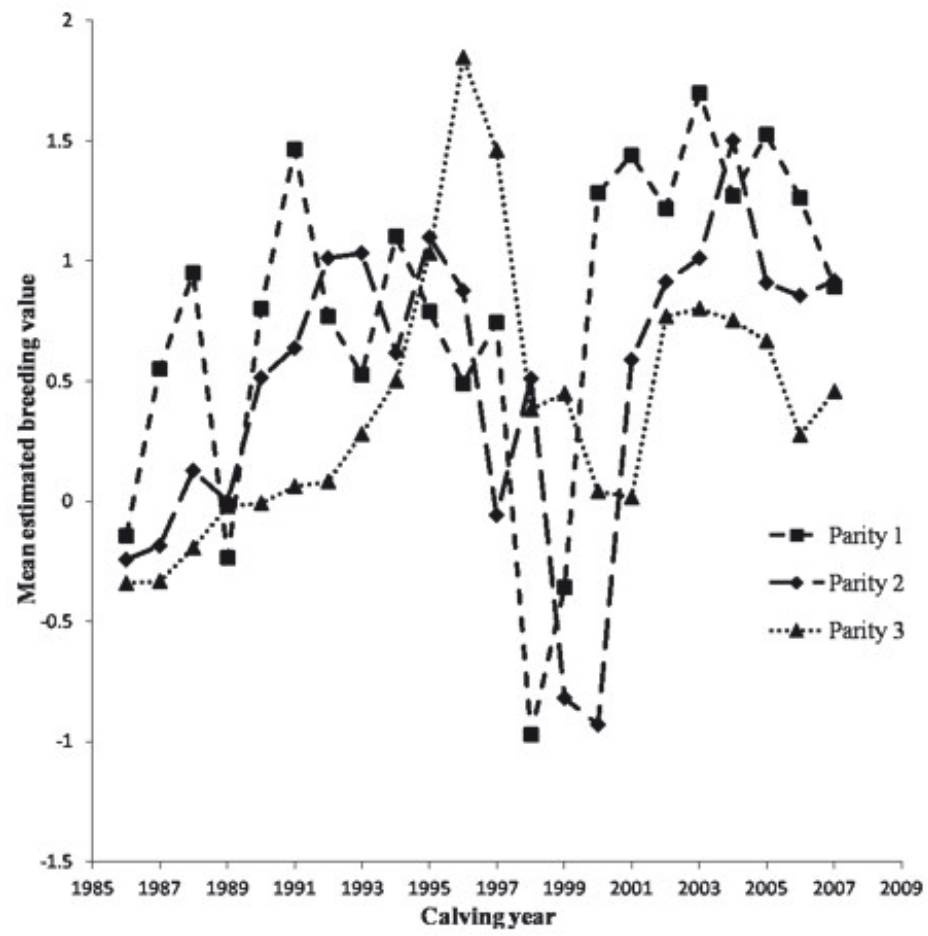

Figure 2

Mean estimated breeding values for lactation lengths in the first three parities by year of calving. 


\section{References}

Ahmed AR, Islam SS, Khanam N, Ashraf A (2004) Genetic and phenotypic parameters of milk production traits of crossbred cattle in a selected farm of Bangladesh. J Biol Sci 4, 452-455

Bajwa IR, Khan MS, Khan MA, Gondal KZ (2004) Environmental factors affecting milk yield and lactation length in Sahiwal cattle. Pak Vet J 24, 23-27

Choudhary V, Kothekar MD, Raheja KL, Kasturiwale NN, Khire DW, Kumar P (2003) Genetic evaluation of first lactation traits in Sahiwal cattle using restricted maximum likelihood technique. Asian-Australian J Anim Sci 16, 639-643

Dematawewa CMB, Pearson RE, VanRaden PM (2007) Modeling extended lactations of Holsteins. J Dairy Sci 90, 3924-3936

Effa K, Wondatir Z, Dessie T, Haile A (2011) Genetic and environmental trends in the long-term dairy cattle genetic improvement programmes in the central tropical highlands of Ethiopia. J Cell Anim Biol 5, 96-104

Ghavi Hossein-Zadeh N, Nejati-Javaremi A, Miraei-Ashtiani SR, Kohram H (2009) Estimation of variance components and genetic trends for twinning rate in Holstein dairy cattle of Iran. J Dairy Sci 92, 3411-3421

Gonzalez-Recio O, Perez-Cabal MA, Alenda R (2004) Economic value of female fertility and its relationship with profit in Spanish dairy cattle. J Dairy Sci 87, 3053-3061

Gonzalez-Recio O, Alenda R, Chang YM, Weigel KA, Gianola D (2006) Selection for female fertility using censored fertility traits and investigation of the relationship with milk production. J Dairy Sci 89, 4438-4444

Ilatsia ED, Muasya TK, Muhuyi WB, Kahi AK (2007) Genetic and phenotypic parameters and annual trends for milk production and fertility traits of the Sahiwal cattle in semi arid Kenya. Trop Anim Health Prod 39, 37-48

Ojango JM, Pollott GE (2001) Genetics of milk yield and fertility traits in Holstein-Friesian cattle on large-scale Kenyan farms. J Anim Sci 79, 1742-1750

Paul AK, Singh I, Bhatia VK (2003) A note on estimation of heritabilities of different dairy characteristics of Kankrej breed by different methods. Indian J Anim Res 37, 153-154

Rahman M, Islam R, Rahman MM, Haque M, Das T (2007) Estimation of genetic parameters for economic traits in dairy cattle of Bangladesh. Asian J Anim Vet Adv 2, 9-14

Steri R, Stanislao Atzori A, Rotondo F, Dimauro C, Cannas A, Macciotta NPP, Pulina G (2010) Genetic, technical and economics aspects of lactation length in dairy cows. Proceedings of the XXVI World Buiatrics Congress, 14-18 Nov., Santiago, Chile, http://www.originalprocess.it/wbc2010/AbstractCD/pdf/528.pdf [last accessed 30.11.2012]

Syrstad O (1993) Milk yield and lactation length in tropical cattle. World Anim Rev 74, 68-72

Tarazon-Herrera MA, Huber JT, Santos JEP, Nussio LG (2000) Effects of bovine somatotropin on milk yield and composition in Holstein cows in advanced lactation fed low- or high-energy diets. J Dairy Sci 83, 430-434

van der Westhuizen RR, Schoeman SJ, Jordaan GF, Van Wyk JB (2001) Genetic parameters for reproductive traits in a beef cattle herd estimated using multitrait analysis. S Afr J Anim Sci 31, 41-48

Vargas B, Koops WJ, Herrero M, van Arendonk JAM 2000. Modeling extended lactations of dairy cows. J Dairy Sci 83, 1371-1380

Wang T, Fernando RI, Kachman DS (2001) MATVEC user's guide. Version 1.03., Department of Biometry, University of Nebraska, Lincoln, USA

Received 21 December 2011, accepted 5 April 2012.

Corresponding author:

Navid Ghavi Hossein-Zadeh

email: nhosseinzadeh@guilan.ac.ir or navid.hosseinzadeh@gmail.com

Department of Animal Science, Faculty of Agricultural Sciences, University of Guilan, Rasht, Iran, P. O. Box: 41635-1314 